\title{
Recorte de episódios históricos para as aulas de matemática: um caminho possível
}

\section{Eliane Maria de Oliveira Araman elianearaman@utfpr.edu.br 0000-0002-1808-2599 \\ Universidade Tecnológica Federal do Paraná, Cornélio Procópio, PR Brasil. \\ Lucas Ferreira Gomes lucasgomis@hotmail.com 0000-0002-4002-2218. \\ Universidade Tecnológica Federa do Paraná, Londrina, PR, Brasil}

\begin{abstract}
RESUMO
Diversas pesquisas defendem que a História da Matemática é recurso didático que pode contribuir tanto para a formação do professor, quanto para a formação dos alunos, no que diz respeito à compreensão do conteúdo e da própria Matemática, dentre outros aspectos. Todavia, mesmo com tais evidências, enquanto recurso didático, ela é pouco explorada na formação do professor, dando-se mais ênfase a uma reflexão sobre os aspectos históricos. Além disso, mesmo que tais sujeitos tenham o interesse em explorá-la em suas aulas, estes se deparam com a falta de material histórico, de orientações didáticas, de sugestões de aulas, entre tantos elementos que contribuem para que esse recurso não seja explorado. Desta forma, o presente artigo tem como objetivo indicar um caminho para se realizarem recortes de episódios históricos, levando em consideração uma reflexão a respeito dos saberes docentes, que, a posteriori, podem ser utilizados em sala de aula. Para tanto, apresenta-se esta proposta, por meio de uma exemplificação: um recorte de episódios históricos sobre geometrias não euclidianas; possibilitando, assim, fazer uma sistematização da proposta.
\end{abstract}

PALAVRAS-CHAVE: História da Matemática. Saberes docentes. Recorte de episódios. Educação Matemática. 


\section{INTRODUÇÃO}

A Matemática apresentada aos alunos, na maioria das vezes, é desvinculada de sua origem, bem como de seus aspectos históricos, dando-se mais ênfase aos procedimentos e técnicas matemáticas, ao invés de uma reflexão a respeito do surgimento destas técnicas e da compreensão dos significados destes procedimentos. Neste viés, o uso da História da Matemática ${ }^{1}$ pode ser uma possibilidade de conduzir o aluno a entender as razões históricas que levaram ao surgimento de determinados conceitos, compreender tais conceitos e, também, como se deu o desenvolvimento deles (BURSAL, 2010). Desta forma, a HM se caracteriza como uma fonte de investigações para as aulas de Matemática; fonte esta que pode atrair os alunos e levá-los e reconhecer que todo conhecimento tem sua história e que a Matemática é uma construção humana (GROENWALD, 2004).

Todavia, mesmo com tais possibilidades promissoras, muitos professores deixam de explorá-las em suas aulas; como destaca Feliciano (2006), muitos documentos que norteiam a educação, como os Parâmetros Curriculares de Matemática (BRASIL, 1998), defendem o uso da HM nas aulas de Matemática; porém, vários professores dizem não utilizar e alguns até desconhecem tal proposta. Neste sentido, ele destaca a necessidade de se incentivar a formação dos professores para o uso da HM. Até mesmo porque alguns dos sujeitos investigados tinham o interesse em seu uso; contudo, não sabiam realizá-lo.

Além disso, Deixa e Salvi (2014) destacam que muitas das orientações expressas em manuais para professores recomendam o uso da HM; todavia, não trazem instruções para seu uso. Assim, mesmo que os professores tenham o interesse de elaborar aulas baseadas na HM, faltam recomendações e, até mesmo, formação para que isso aconteça (FELICIANO, 2006). Mediante estas reflexões é que este trabalho foi desenvolvido, o qual tem como objetivo propor um caminho para se realizar recortes de episódios históricos, que podem ser utilizados em sala de aula. Cabe salientar que, na perspectiva que se tem, realizar um recorte de episódios históricos é olhar para a história em sua totalidade e selecionar os fatos considerados mais relevantes que permitiram a criação de determinadas ideias ou conceitos que se pretendem abordar, de modo que seja possível elaborar uma sucessão de acontecimentos em forma de narrativa (episódio), que seja coerente com o público alvo (professores, alunos dos diferentes níveis e modalidades de ensino, comunidade científica, entre outros).

Sendo assim, o intuito do presente trabalho é auxiliar os professores a olharem para a história dos fatos, acontecimentos, descobertas, entre outros elementos relacionados ao surgimento dos conceitos matemáticos e fazer uso destas informações, o que pode contribuir para que a HM seja implementada nas aulas de Matemática, independentemente do nível ou modalidade de ensino.

A presente proposta baseia-se nos pressupostos dos saberes docentes defendidos por Tardif (2013), para quem são os saberes mobilizados pelos professores no decorrer de suas ações pedagógicas. Desta maneira, destaca-se que nesta sugestão não se propõe, apenas, a escolha de textos históricos aleatórios para serem levados para as aulas de Matemática, mas uma forma de olhar para estes textos e realizar recortes, levando em consideração o conteúdo a

Página Us 275 aremos a abreviação HM para remeter a este termo. 
ser abordado, as orientações curriculares para este conteúdo, a história do conteúdo e as indicações didáticas para o uso da HM em sala de aula, elementos que, em nossa perspectiva, constituem-se como saberes docentes.

Por fins didáticos, apresenta-se tal sugestão por meio de uma exemplificação: o recorte de dois episódios históricos sobre as geometrias nãoeuclidianas; para que, então, seja formalizada a proposta: um caminho possível para se realizar recortes de episódios históricos que podem ser levados para as aulas de Matemática.

\section{A HISTÓRIA DA MATEMÁTICA}

Pesquisadores como Furinguetti (2007), Brito e Carvalho (2009), Bursal (2010), Mendes (2006), Mendes e Chaquiam (2016), entre tantos outros, defendem que um estudo histórico dos diversos tópicos de Matemática pode contribuir para o aprimoramento do conhecimento do professor, e, por conseguinte, na atuação deste sujeito em sala de aula. As potencialidades da introdução de uma perspectiva histórica na formação de professores justificamse na possibilidade de uma aproximação cultural à Matemática poder conduzir a uma mudança efetiva das práticas de ensino ou, pelo menos, a uma modificação da forma como se concebe o ensino da Matemática (FURINGUETTI, 2007).

Os conhecimentos advindos da HM devem fazer parte da formação do professor para que eles tenham elementos que possibilitem mostrar a seus alunos que a Matemática não é uma ciência repleta de verdades eternas, infalíveis e imutáveis, mas uma ciência aberta à incorporação de novos conhecimentos (BRASIL, 1998). Por isso, este recurso didático tem muito a contribuir, tanto para a formação quanto para a ampliação da prática docente do professor em sala de aula. Neste sentido, a HM pode ser empregada como um recurso didático para se explorar a Matemática em qualquer nível de ensino, já que a partir dela é possível contextualizar, humanizar, motivar e auxiliar na compreensão de conceitos. Sendo essa uma das alternativas para se quebrar com o paradigma atual do ensino desta ciência, em que o:

[...] modo de pensar a Matemática tem trazido como consequência a desvalorização, no ensino da Matemática, da história da matemática e de toda Matemática não formalizada de acordo com determinados padrões acadêmicos. O esforço de isentar a construção do conhecimento matemático de dúvidas e contradições tem reforçado a ideia da Matemática como uma área de conhecimento independente das demais disciplinas que compõem o currículo escolar, em especial da educação básica (STAMATO, 2003, p. 23).

Ademais, por intermédio da HM, pode-se apresentar a forma como os conceitos matemáticos foram criados, evidenciando que tal criação aconteceu em contextos e momentos diferentes, produzidos, muitas vezes, a partir da necessidade do homem de resolver seus problemas, permitindo, assim, a compreensão de que a Matemática é uma construção humana. Corroborando estas ideias, Groenwald (2004, p.47) afirma que a HM é um recurso didático:

[...] que permite ao aluno descobrir a gênese dos conceitos e métodos que aprenderá em aula. Em outras palavras este enfoque permitirá ao aluno 
Acrescenta-se a tais indicações o fato de que documentos que norteiam a educação básica também defendem a inserção da HM nas aulas de Matemática, em especial os Parâmetros Curriculares Nacionais - PCN (BRASIL, 1998, p. 42) que dentre as suas orientações afirma que:

A História da Matemática pode oferecer uma importante contribuição ao processo de ensino e aprendizagem dessa área do conhecimento. Ao revelar a matemática como uma condição humana, ao mostrar as necessidades e preocupações de diferentes culturas, em diferentes momentos históricos, ao estabelecer comparações entre conceitos e processos matemáticos do passado e do presente, o professor cria condições para que o aluno desenvolva atitudes e valores mais favoráveis diante desse conhecimento. Além disso, conceitos abordados em conexão com sua história constituem veículos de informação cultural, sociológica e antropológica de grande valor formativo. A História da Matemática é, nesse sentido, um instrumento de resgate da própria identidade cultural.

Seguindo este pensamento, Miguel e Miorim (2004) ressaltam que uma utilização adequada da História, aliada ao conhecimento matemático e suas aplicações, pode levar os alunos a compreender que:

A matemática é uma criação humana; 2) As razões pelas quais as pessoas fazem matemática; 3) As conexões da matemática com outros áreas; 4) Necessidades práticas, sociais, econômicas e físicas estimulam desenvolvimento matemático; 5) A curiosidade estritamente intelectual leva a generalização de ideias; 6) Mudança na percepção dos objetos matemáticos; 7) Abstração em relação a generalização da história do pensamento matemático; 8) A natureza de uma estrutura, de uma axiomatização e de uma prova (MIGUEL; MIORIM, 2004, p. 33).

No entanto, mesmo com a evidência de tantos contributos para a aprendizagem da Matemática, muitos professores não exploram este recurso didático em suas aulas, como já se destacou, os quais exprimem muitas dificuldades ao explorar a HM em sala de aula, dentre elas:

- Ausência de uma disciplina específica de HM em muitos cursos de licenciatura no Brasil (STAMATO, 2003).

- Os professores não sabem como abordá-la (FELICIANO, 2006).

- Propostas de aulas vinculadas a HM são poucas e as existentes dificilmente chegam aos professores (FELICIANO, 2006).

- Faltam orientações metodológicas para o uso da $\mathrm{HM}$ em sala de aula (DEIXA; SALVI, 2014).

- Dificuldade de acesso aos materiais históricos (DEIXA; SALVI, 2014; MIGUEL; MIORIN, 2008).

- Mesmo que os professores possuam materiais históricos os professores, não sabem como fazer o recorte deste material (MAN-KEUNG, 2004).

Não são apenas estas dificuldades, Deixa e Salvi (2014) destacam outras que são expressas pelos próprios professores, as quais corroboram para que muitos docentes não consigam elaborar aulas utilizando a HM. Sendo este um grande 
problema para a Educação Matemática, visto que a $\mathrm{HM}$ tem muito a auxiliar na formação do aluno, como mencionado; todavia, se os professores deixam de usála, ela deixa de exercer tais contribuições.

Mediante essa dificuldade de encontrar orientações para se explorar a HM em sala de aula, buscamos na literatura alguns textos que podem nortear os professores em relação a esse uso. Estes textos abarcam algumas estratégias de uso, trazem experiências de sala de aula de inserção da HM, exemplos de atividades baseadas na HM, entre outros elementos, que, entende-se, são indispensáveis para o uso da $\mathrm{HM}$ em sala de aula:

Quadro 1 - Indicações de leitura para o uso da HM em sala de aula.

TEXTOS

SAMPAIO, H. R. Uma abordagem histórico-filosófica na educação matemática: contribuições ao processo de aprendizagem em trigonometria no ensino médio. 2008. 190f. Dissertação (Mestrado em Ensino de Ciências e Educação Matemática) - Universidade Estadual de Londrina, Londrina, 2008. Link: http://www.bibliotecadigital.uel.br/document/?view=vtls000129986

LIMA FILHO, R. R. C. Um estudo de práticas matemáticas históricas e sugestões de uso na matemática escolar. 2013. 147 f. Dissertação (Mestrado em Ensino de Ciências Naturais e Matemática) - Universidade Federal do Rio Grande do Norte, Natal, 2013.

Link: https://repositorio.ufrn.br/ispui/bitstream/123456789/16098/1/RenatoRCLF DISSERT.pdf

SILVA, A. P. P. N. A leitura de fontes antigas e a formação de um corpo interdisciplinar de conhecimentos: um exemplo a partir do Almagesto de Ptolomeu. 2013. 100 f. Dissertação (Mestrado em Ensino de Ciências Naturais e Matemática) - Universidade Federal do Rio Grande do Norte, Natal, 2013.

Link: https://repositorio.ufrn.br/jspui/bitstream/123456789/16105/1/AnaPPNS DISSERT.pdf

MENDES, I. A. História para o ensino da matemática: uma reinvenção didática para a sala de aula. Revista Cocar, n. 3, p. 145-166, 2017.

Link: https://paginas.uepa.br/seer/index.php/cocar/article/view/1167/718

SAITO, F. História e ensino de matemática: construindo interfaces. In: J. Flores Salazar \& F. Ugarte Guerra (eds.). Investigaciones en Educación Matemática. Lima: Fundo Editorial PUCP, 2016, p. 237291. Link: https://revistas.pucsp.br/index.php/emd/article/view/29002/20273

BATISTA, I. L.; LUCCAS, S. Abordagem histórico-filosófica e Educação Matemática-uma proposta de interação entre domínios de conhecimento. Educação Matemática Pesquisa, v. 6, n. 1, 2004.

Link: http://www.uel.br/grupo-pesquisa/ifhiecem/arquivos/4682-10997-1-PB.pdf

WOTTRICH, S. C. História da Matemática como um recurso metodológico no ensino de fração. Link:

http://bibliodigital.unijui.edu.br:8080/xmlui/bitstream/handle/123456789/2700/historia\%20da\%20 matematica\%20como\%20um\%20reurso\%20metodologico\%20no\%20ensino\%20de\%20fra\%C3\%A7a o.pdf?sequence $=1$

(Fonte: Dados da pesquisa)

Contribuindo com tais indicações, emerge a proposta apresentada, tendo como finalidade cooperar para que os professores tenham um caminho que os auxilie no recorte de textos históricos, tendo assim subsídios para inserir a HM em suas aulas.

\section{OS SABERES DOCENTES}

Entende-se neste trabalho que ação docente é um conjunto de diversos afazeres, tais como: preparar aulas, propor estratégias, avaliar, organizar a sala de aula, escolher materiais, planejar, entre tantas outras tarefas, o que exige que os profissionais ajam de forma diferenciada e em momentos diferenciados, aplicando, assim, habilidades diversas. Desta forma, pode-se dizer que os professores, no decorrer dessas ações, empregam saberes diversificados. 
Discussões que remetem aos saberes mobilizados pelos professores em sua prática pedagógica têm propiciado o desenvolvimento de diversas pesquisas, como Gauthier (2006) e Tardif (2013). Estes e outros pesquisadores defendem que a profissionalização da atividade docente deve identificar os saberes próprios do ensino, levando em consideração os contextos em que estes saberes se efetivam, visto que estes trazem uma marca muito forte para a ação destes sujeitos, influenciando nas tomadas de decisões, bem como nas escolhas realizadas.

Os saberes docentes "formam uma espécie de reservatório" que o professor pode abastecer para atender às necessidades que a prática docente exige (GAUTHIER, 2006). Seguindo esta ideia, Tardif e Gauthier (1996, p. 11) defendem que "o saber docente é um saber composto de vários saberes", os quais são responsáveis pela estruturação do conhecimento dos professores, e, por isso, influenciam em suas práticas.

Segundo Tardif (2013, p. 36), esse saber é um "saber plural, formado pela amálgama, mais ou menos coerente, de saberes oriundos da formação profissional e de saberes disciplinares, curriculares e experienciais". Além disso, cabe destacar que estes saberes são provisórios, pessoais e evoluem com o tempo (TARDIF; GAUTHIER, 1996), isto se deve ao fato de que eles podem modificar-se e aprimorar-se mediante a troca de experiências e com a própria prática da sala de aula.

Entretanto, os saberes não são oriundos apenas da formação inicial ou continuada, mas são constituídos a partir de inúmeras fontes, principalmente da prática docente (TARDIF, 2013). Percebe-se que estes saberes são plurais e cada um com a sua especificidade, já que contemplam todas as ações que os professores devem desempenhar no decorrer de seu trabalho. Outro aspecto a considerar, segundo Campelo (2001, p. 51), é que apesar de utilizarem diversas nomenclaturas para designar esses saberes todas estas pesquisas têm os mesmos objetivos, que são os de contribuir para:

a) confirmar a construção e o reconhecimento da identidade profissional do docente;

b) formar professores para desenvolverem um ensino, a cada dia, mais coerente com os fins da educação socialmente estabelecidos, apesar das diversidades que marcam a sua vida e o seu trabalho.

Assim, é possível entender que o estudo destes saberes tem como finalidade corroborar para a formação do professor, por meio de uma reflexão sobre a sua identidade.

No que diz respeito ao professor de Matemática, Blanco (2003, p. 70) destaca que o conhecimento deste profissional "está relacionado com os contextos e situações em que ele irá utilizar tal conhecimento, isto é, com atividades, objetivos educacionais e contextos de Matemática". Assim, para que os professores se sintam aptos para conduzir a aprendizagem de seus alunos, torna-se necessária uma formação que possibilite a eles desenvolverem seus saberes relacionados aos conteúdos, bem como os relacionados à prática do ensino de Matemática.

Por meio dessas reflexões, encontramos nos saberes docentes elementos 
que possibilitaram criar um caminho para se realizar recortes de episódios históricos, considerando três das tipologias de saberes sugeridas Tardif (2013), as quais são:

- Os saberes da formação profissional: São constituídos pelo conjunto de saberes da formação profissional, isto é, dos conhecimentos pedagógicos relacionados às técnicas e métodos de ensino (saber fazer), que são legitimados cientificamente e são explorados no processo de formação do professor, seja ela inicial ou continuada (TARDIF, 2013). Assim, neste trabalho, considera-se que, antes de tentar fazer um recorte histórico, o professor deve conhecer as orientações que a formação, enquanto recurso didático, propõe.

- Os saberes disciplinares: São os saberes reconhecidos e identificados como pertencentes a um determinado campo de conhecimento (ciências humanas, ciências exatas, ciências biológicas etc.), além disso, são produzidos e acumulados pela humanidade ao longo de sua história, são administrados pela comunidade científica e o acesso destes se dá por meio das instituições educacionais (TARDIF, 2013). Desta forma, este se caracteriza pelo conjunto de conceitos elaborados pelos povos ao longo de sua história, os quais são divulgados, principalmente, pelas instituições escolares. Dessa forma, para se realizar um recorte de episódios históricos, elenca-se que o professor deve conhecer o conteúdo que irá abordar, e, além disso, ele deve investigar e compreender os aspectos históricos desse conteúdo.

- Os saberes curriculares: São os saberes relacionados à forma como as instituições educacionais fazem a gestão dos conhecimentos produzidos e que devem ser transmitidos aos estudantes. Assim, são apresentados, concretamente, sob forma de programas escolares ou orientações curriculares (documentos que apresentam objetivos, conteúdos e métodos) que os professores devem aprender e aplicar. Assim sendo, o professor deve conhecer quais são as orientações que estes documentos trazem sobre o que deve ser ensinado e em que nível, que metodologia pode ser empregada no ensino destes conteúdos, bem como os objetivos a serem alcançados (TARDIF, 2013). Para tanto, destaca-se que, para se realizar o recorte de episódios históricos, o professor deve compreender o que os documentos norteadores da educação nacional dizem a respeito do tópico que se pretende abordar, bem como se a HM pode ser empregada no ensino do mesmo e, até mesmo, julgar se com ela será possível atingir os objetivos previamente definidos.

\section{PROCEDIMENTOS METODOLÓGICOS}

Considera-se a abordagem qualitativa a mais adequada para a pesquisa realizada. Segundo Bogdan e Biklen (1994), uma investigação de caráter qualitativo é descritiva e seu interesse maior está no processo de investigação, e não, apenas, nos resultados obtidos.

Acrescenta-se ainda que, para estes autores, neste tipo de pesquisa nada deve ser considerado como trivial, mas que "tudo tem potencial para constituir uma pista que nos permita estabelecer uma compreensão mais esclarecedora do nosso objeto de estudo" (BOGDAN; BIKLEN, 1994, p. 43). Para Garnica (2004, p. 86), algumas características de uma pesquisa como esta são: 
(a) a transitoriedade de seus resultados; (b) a impossibilidade de uma hipótese a priori, cujo objetivo da pesquisa será comprovar ou refutar; (c) a não neutralidade do pesquisador que, no processo interpretativo, vale-se de suas perspectivas e filtros vivenciais prévios dos quais não consegue se desvencilhar; (d) que a constituição de suas compreensões dá-se não como resultado, mas numa trajetória em que essas mesmas compreensões e também os meios de obtê-las podem ser (re)configuradas; e (e) a impossibilidade de estabelecer regulamentações, em procedimentos sistemáticos, prévios, estáticos e generalistas.

Em busca de elaborar um caminho para se realizar recortes de episódios históricos que podem ser usados em aulas de Matemática, procuramos levantar na literatura subsídios para elaborar tal proposta; assim, encontraram-se nos saberes docentes e suas tipologias, apresentados por Tardif (2013), elementos que possibilitaram construir uma sugestão.

Como já se destacou, dentre as tipologias dos saberes docentes, foi possível identificar nos saberes da formação pedagógica, nos saberes disciplinares e nos saberes curriculares aspectos indispensáveis à compreensão do professor para se realizar um recorte. A partir desses aspectos, foi possível sistematizar um esquema com os saberes necessários para se realizar o recorte de episódios históricos em nossa proposta:

Figura 1 - Saberes necessários para o recorte.

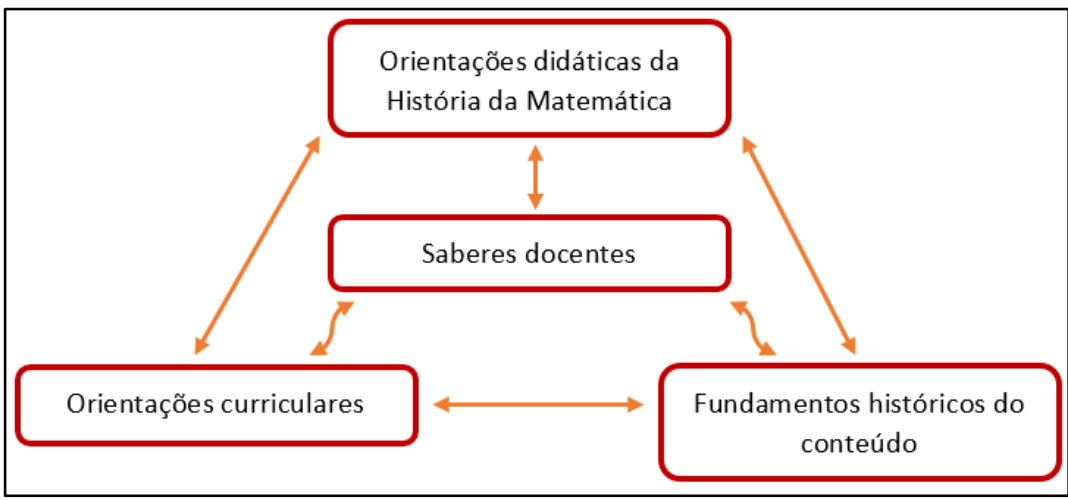

(Fonte: Dados da pesquisa)

Antes de formalizar este caminho para se fazer recortes históricos, será explorada uma exemplificação: um recorte de dois episódios históricos relacionados à origem e aos conceitos das geometrias não euclidianas, os quais são:

- Episódio 1: O surgimento das geometrias não euclidianas.

- Episódio 2: Retas paralelas nas geometrias não euclidianas.

Para tanto, apresentam-se o recorte realizado e a justificativa para este seguindo como pressuposto:

- As orientações curriculares: o que defendem as Diretrizes Curriculares de Matemática do Estado do Paraná (PARANÁ, 2008) e os Parâmetros Curriculares Nacionais de Matemática (1998) a respeito das geometrias não euclidianas e o seu ensino (vinculado aos saberes curriculares).

- Os fundamentos da história: os aspectos históricos das geometrias não euclidianas (vinculado aos saberes disciplinares). 
- As orientações didáticas: os que dizem as pesquisas desenvolvidas sobre os aspectos didáticos da HM para o ensino de Matemática (vinculado aos saberes da formação pedagógica).

Esta exemplificação permite formalizar e apresentar tal proposta, destacando passo a passo como proceder para se realizar este tipo de recorte de episódios históricos, simplificando-o em forma de um esquema.

\section{RECORTE DE EPISÓDIOS HISTÓRICOS DAS GEOMETRIAS NÃO EUCLIDIANAS}

Neste tópico, apresenta-se um recorte de episódios históricos das geometrias não euclidianas, mas especificamente sobre a origem destas, além da origem de conceitos das geometrias hiperbólica e elíptica, tal recorte foi feito a partir das reconstruções históricas realizadas por Barbosa (2011), Ribeiro (2012) e Katz (2011). A escolha dessas fontes se deu pelo fato de que estas reconstruções traziam a história de uma forma que pudesse ser lavada para a sala de aula, com imagens claras, traduções mais próximas ao original, definições acessíveis, entre outros aspectos. Para cada recorte é apresentada uma justificativa que o fundamenta, seguindo a estratégia que é formalizada mais adiante.

\section{Episódio 1: O surgimento das geometrias não euclidianas}

As geometrias não euclidianas surgiram a partir da própria geometria euclidiana plana, que teve como seu grande precursor Euclides. Pouco se sabe sobre ele e muitos duvidam da sua existência, mas, de acordo com Nobre (2009), Euclides viveu entre 325 a.C. e 265 a.C. na cidade egípcia de Alexandria, sendo professor da Biblioteca e Museu de Alexandria. Euclides foi autor de uma das maiores obras da Matemática e um dos textos matemáticos mais importantes da época grega, escrito há cerca de 2300 anos, chamado Os Elementos.

Esta obra é uma coleção de treze livros, mas não apresenta uma estrutura unificada, sendo caracterizada por um compêndio, que foi organizado por Euclides a partir de muitas obras existentes sobre várias áreas da Matemática incluídas no trabalho.

Tais livros são compostos por definições (são enunciados que explicam os significados de cada termo), postulados ou axiomas (são proposições que não se demonstram e que servem de base para o desenvolvimento de uma teoria, que, nesse caso, algumas se relacionam às noções primitivas de ponto, reta e plano) e teoremas (são preposições que necessitam de demonstração e complementam o desenvolvimento da teoria) (GARBI, 2010).

É no primeiro dos treze livros de Os Elementos que se encontram os cinco famosos postulados que deram forma à "Geometria Euclidiana Plana" ou "Geometria Plana". Além disso, ele traz 23 definições e 9 noções comuns. São os postulados: 
O quinto postulado trouxe grandes repercussões entre os matemáticos que se dedicaram a tentar prová-lo, até mesmo porque, segundo Brito (1995), Proclo, um grande comentarista de Os Elementos no século $\mathrm{V}$, percebeu que as 28 primeiras proposições do trabalho (465 no total) são demonstradas sem empregar este postulado, sendo que algumas seriam facilmente demonstradas se o quinto postulado fosse utilizado - isso pode indicar que até Euclides tentava "evitar" seu uso (KATZ, 2011).

A Figura 2 ilustra o quinto postulado de Euclides. 0 postulado diz que se $\alpha+$ $\beta<180^{\circ}$, então as restas $r$ e s irão se encontrar:

Figura 2 - $\mathrm{O}$ quinto postulado.

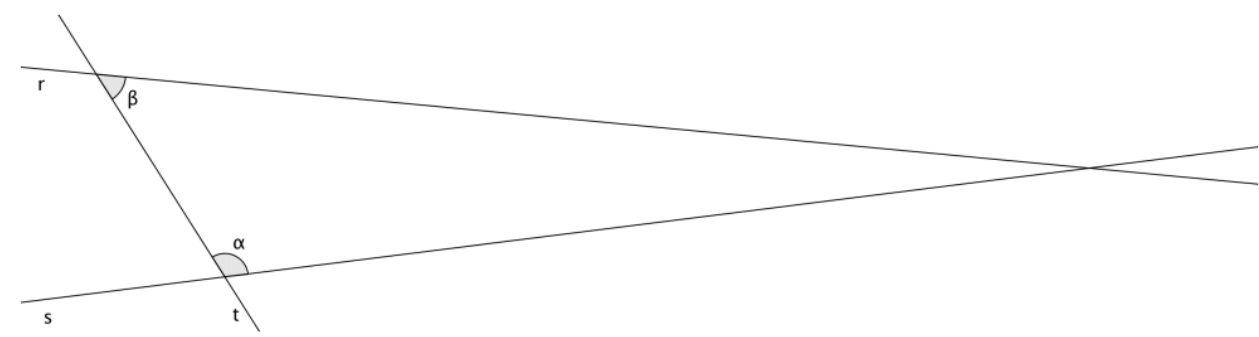

(Fonte: Ribeiro, 2012, p. 36)

Diversos são os matemáticos que tentaram prová-lo, dentre eles: Ptolomeu I, Proclo, o árabe Nasis Eddin All Tusin, John Wallis, o padre jesuíta Girolamo Saccheri (o primeiro a publicar), Joahnn Heinrich Lambet, Adrien Marie Legendre, entre tantos outros (BARBOSA, 2011). Muitos também tentaram reescrevê-lo ou criar proposições equivalentes, sendo a mais famosa a proposta por John Playfair (1748-1819), que ficou conhecida como postulado das paralelas, que diz que "por um ponto fora de uma reta pode-se traçar uma única reta paralela à reta dada" (BARBOSA, 2011, p. 29).

Apesar de todas as investigações e tentativas, não foi possível prová-lo; porém, séculos mais tarde (XVIII e XIX), alguns matemáticos compreenderam que o quinto postulado de Euclides, além de não poder ser provado, poderia ser negado sem que contradições acontecessem. Neste episódio ganham destaque Nikolay Ivanovich Lobachevsky (1792-1856), János Bolyai (1802-1860) e Cal Friedrich Gauss (1777-1855), que percebem que, ao negar ou substituir o quinto postulado por outro, surgiria uma nova geometria, tão válida quanto a de Euclides (BARBOSA, 2011). Isso abriu caminho para que novas geometrias surgissem e hoje se entende por geometria não euclidiana, como qualquer geometria que contradiz, ao menos, um dos postulados de Euclides (PARANÁ, 2008).

\section{Justificativa para o recorte:}

- Orientações curriculares: De acordo com as DCE de Matemática (PARANÁ, 2008), é preciso que as noções básicas das geometrias não euclidianas sejam abordadas, além disso afirmam que ao explorar esta temática a HM pode ser explorada.

- Fundamentos históricos do conteúdo: Para Hansem (1998), a descoberta de um ramo novo, mostrando que a geometria de Euclides não era uma verdade incontestável que até então se supunha ser; desta forma, ela abriu um 
caminho de discussões para diversas áreas da ciência e para a própria Matemática.

- Orientações didáticas da História da Matemática: De acordo com Mendes e Chaquiam (2016), deve-se explorar as histórias relacionadas aos aspectos matemáticos em seu processo de criação, reinvenção e organização lógica, estabelecido no tempo e no espaço com a finalidade de sistematizar soluções de problemas de ordem sociocultural e científica, em todos os tempos e lugares; e no que diz respeito às geometrias não euclidianas, Hansem (1998) propõe que, inicialmente, deve-se apresentar o contexto histórico que possibilitou estas geometrias surgirem: o quinto postulado de Euclides.

\section{Episódio 2: Retas paralelas nas geometrias não euclidianas}

Parte-se do conceito de retas paralelas: na geometria euclidiana plana, Bonola (1955) diz que duas retas são paralelas se elas não possuem interseção e estão em um mesmo plano, isto é, são equidistantes. Todavia, Lobachevsky, em meados de 1820, define retas paralelas como "todas as linhas retas que num plano partem de um ponto e podem, relativamente a uma linha reta do mesmo plano, ser divididas em duas classes - as que cortam e as que não cortam. As linhas fronteiras de uma e outra classe são chamadas paralelas à linha dada" (KATZ, 2011, p. 1001). Em suma, Lobachevsk propõe que dada uma reta $r$ e um ponto $P$ fora dela existem infinitas retas que passam por esse ponto, tais retas são divididas em duas classes: as que cortam $r$ e as que não cortam $r$; as linhas de fronteira que separam essas duas classes de reta são chamadas de retas paralelas à reta dada. Na Figura 3, apresenta-se essa ideia, na qual as retas paralelas à reta $r$ dada são s e $t$ (linhas não tracejadas), isto é, a geometria Lobachevskyana adota a existência de, ao menos, duas retas paralelas a uma reta dada passando por um ponto dado:

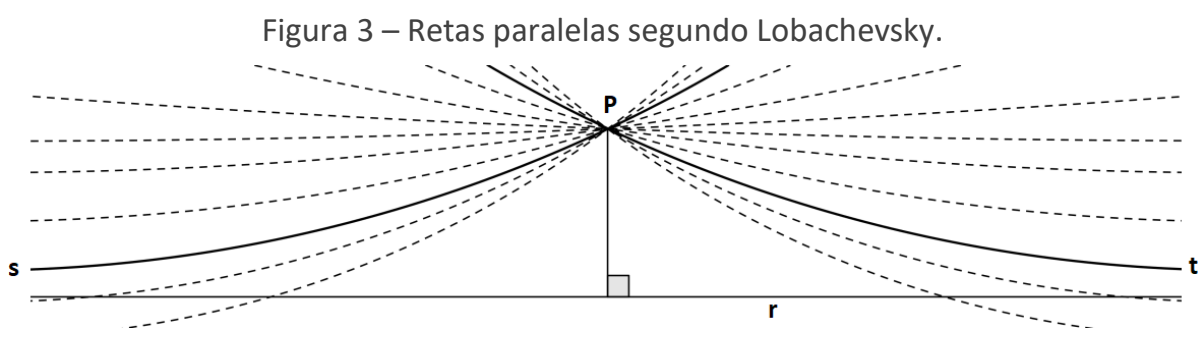

(Fonte: Ribeiro, 2012, p. 51)

Segundo Bonola (1912), Lobachevsky alterou o postulado das paralelas pelo que hoje é chamado de postulado hierbólico: por um ponto fora de uma reta dada passa mais de uma reta que não intercepta a primeira. Daí a definição de retas paralelas adotadas por ele. As principais propriedades deduzidas por Lobachevsky são:

- $\quad$ Se uma reta $s$ é paralela a $r$ no ponto $P$, então $s$ será paralela a $r$ em qualquer ponto de s na mesma direção.

- Se s é paralela a r, então $r$ é paralela a s.

- Se r é paralela a s e s é paralela a t, então ré paralela a t.

- Se r é paralela a s, então r é assintótica a s (BONOLA, 2012, p. 87-88).

Já Bolyai, definiu o conceito de paralela assintótica, que é a primeira reta que não cruza outra dada, quando se altera continuamente sua inclinação em 
relação a outra (RIBEIRO, 2012). Na figura 3, apresenta-se essa ideia, isto é, inclina-se a reta $\mathrm{BC}$ até que esta deixe de interceptar a outra reta:

Figura 4 - Retas assintótica.

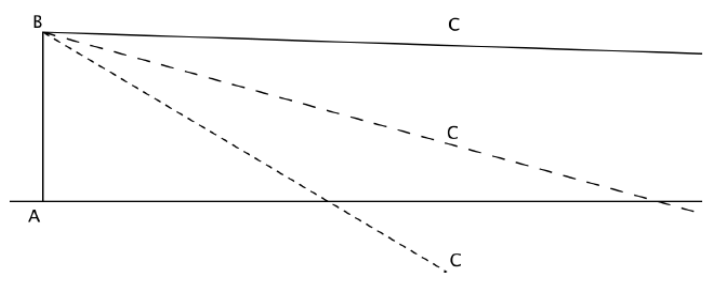

(Fonte: Ribeiro, 2012, p. 54)

Todos esses elementos são válidos na geometria hiperbólica; porém, na geometria elíptica, Riemann propôs que dado dois pontos $A$ e $B$, denomina-se circunferência máxima que passa por esses pontos, as retas que são círculos máximos, também chamadas de geodésicas. Além disso, em qualquer esfera dois círculos máximos se interceptam em mais de um ponto. Como na imagem a seguir, dados os círculos máximos, ou seja, as retas $A E A^{\prime}$ e $A D A^{\prime}$ se interceptam nos pontos $A$ e $A^{\prime}$, estas são ditas extremidades de um mesmo diâmetro da esfera (COUTINHO, 2001).

Figura 5 - Geodésicas na superfície esférica.

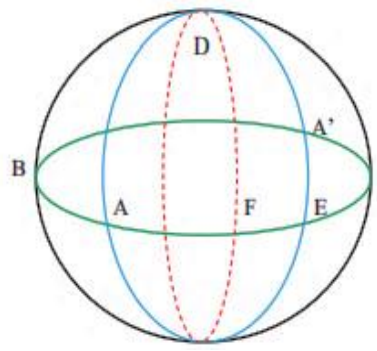

(Fonte: Os Autores)

Isso é uma consequência da proposta para substituir o quinto postulado de Euclides por: dada uma reta $r$ e um ponto $P$ que não pertence a $r$, não existe nenhuma reta paralela à $r$ que passe por $P$ (RIBEIRO, 2012), que claramente pode ser substituído por retas paralelas não existem, tal postulado está ilustrado na Figura 6:

Figura 6 - Postulado proposto por Riemann.

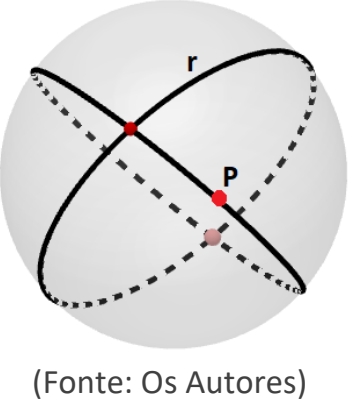

Outro postulado proposto por Riemann é dado dois pontos sobre a esfera, pode-se encontrar infinitas retas que passa por esses dois pontos (COUTINHO, 
2001).

\title{
Justificativa para o recorte:
}

- Orientações curriculares: Segundo as DCE de Matemática (PARANÁ, 2008), uma das possibilidades é explorar os conceitos da geometria hiperbólica por meio do postulado de Lobachevsky, e, também, "na apresentação da geometria elíptica, fundamentá-la através do seu desenvolvimento histórico e abordar: postulado de Riemann; curva na superfície esférica e discutir o conceito de geodesia; círculos máximos e círculos menores" (PARANÁ, 2008, $p, 57)$.

- Fundamentos históricos do conteúdo: O quinto postulado de Euclides ou postulado das paralelas foi o principal motivador do surgimento das geometrias não euclidianas; desta forma, Ribeiro (2012) destaca que a ideia de paralelismo seja um dos elementos a serem explorados, dando ênfase ao postulado de Lobachevsky que possibilitou o surgimento da geometria hiperbólica e o postulado de Riemann que possibilitou o surgimento da geometria elíptica.

- Orientações didáticas da História da Matemática: De acordo com Mendes e Chaquiam (2016), é preciso extrair das informações históricas a explicação de porquês matemáticos, que pode contribuir para o interesse de estudos futuros por parte dos alunos. Nesta perspectiva, eles destacam que os modelos matemáticos criados ou reformulados em determinadas épocas podem ser fontes inspiradoras que o professor pode levar para sala de aula.

\section{FORMALIZAÇÃO DA PROPOSTA}

Para corroborar o uso da história da matemática em sala de aula, reconhecer a Matemática como criação humana e conectar a Matemática as atividades humanas, entende-se que:

\begin{abstract}
As ideias matemáticas comparecem em toda evolução da humanidade, definindo estratégias de ação para lidar com o ambiente, criando e desenhando instrumentos para esse fim, e buscando explicações sobre os fatos e fenômenos da natureza para a própria existência. Em todos os momentos da história e em todas as civilizações, as ideias matemáticas estão em todas as formas de fazer e saber fazer (D’AMBRÓSIO, 1999, p. 97).
\end{abstract}

Assim, é possível compreender que tais ideias devem ser exploradas no contexto de sala de aula, a fim de que contribuam para o ensino de Matemática. Para tanto, a partir dos recortes apresentados anteriormente, bem como das justificativas expostas, sugere-se um caminho que pode ser seguido para se fazer recortes de textos históricos com vistas a serem explorados nas aulas de Matemática. Tal caminho leva em consideração os saberes docentes e suas orientações, que já foram explicitados e sintetizados a partir do seguinte esquema: 


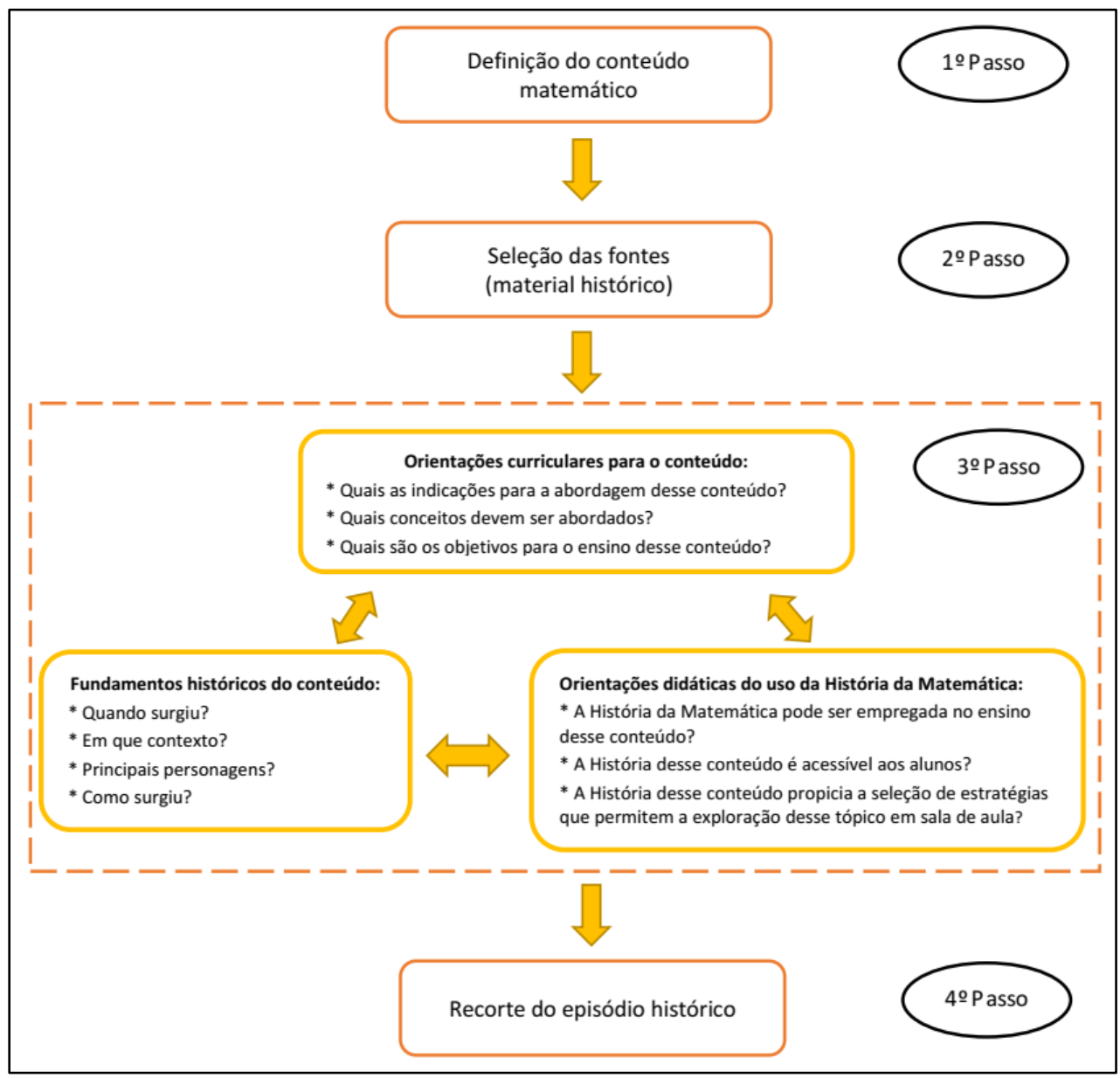

(Fonte: Dados da pesquisa)

Observa-se no diagrama que a sugestão para o recorte de um episódio histórico consiste em alguns passos a serem seguidos:

- 10 Passo: Delimitação do conteúdo que se pretende abordar no recorte.

- 2o Passo: Seleção dos materiais históricos, que são as fontes que fornecerão as informações históricas para se realizar o recorte.

Para Mendes e Chaquiam (2016), essa seleção deve ser rigorosa e fontes duvidosas devem ser evitadas. Segundo Nobre (2004), fontes duvidosas são aquelas que podem trazer informações incorretas, desatualizadas, modificadas ideologicamente, isto é, elementos que podem comprometer a veracidade daquilo que está sendo exposto.

Mendes e Chaquiam (2016) destacam que se pode utilizar livros de HM (que trazem reconstruções históricas dos conceitos matemáticos), como o livro "História da Matemática: uma visão crítica" de Tatiana Roque (2012), que além de ser escrito por uma brasileira, é baseado em pesquisas históricas recentes e confiáveis; tese ou dissertações nas quais os pesquisadores da área se propõem em realizar reconstruções históricas (pode-se utilizar o banco de teses e dissertações da $\mathrm{CAPES}^{2}$ para a seleção de trabalhos); revistas (pode-se utilizar o portal de periódicos da CAPES $^{3}$ para a seleção de artigos); textos originais (que 
com uma pesquisa criteriosa na internet podem ser encontrados, como em repositórios digitais das universidades).

Destaca-se que quanto mais atuais forem esses textos historiográficos, melhor poderá ser a confiabilidade das informações apresentadas, pois além de novas tendências historiográficas e metodologias históricas terem surgido, novas interpretações históricas têm sido propostas.

- 3o Passo: Julgar as informações apresentadas nestes materiais a partir das orientações curriculares, fundamentos históricos do conteúdo e orientações didáticas da HM que foram destacadas anteriormente, isto é, a partir desse julgamento, deve-se fazer a seleção das informações contidas nos materiais históricos que vão ao encontro dessas orientações.

Em suma, para o recorte, deve-se retirar o contexto no qual os conceitos referentes ao tema em questão surgiram (Tentar responder aos seguintes questionamentos: Quando? Em que lugar? Quais os elementos culturais da época? Entre outros elementos que remetem ao contexto sociocultural); os principais personagens que contribuíram para criação dos conceitos (Tentar responder aos questionamentos: Quem era? O que fez? Quando fez? Como fez? Entre outras perguntas); levantar do tema os conceitos matemáticos que foram criados (Tendo em vista responder aos questionamentos: Como este conceito foi definido? Como era utilizado? Houve alguma modificação ao longo do tempo? Qual o impacto da criação deste conceito para a Matemática? Entre outros questionamentos que podem ser realizados); outros elementos também podem surgir como interdisciplinaridade com outras áreas, impactos em outros campos fora da Matemática etc., que podem ser explorados no recorte a ser realizado.

- 40 Passo: A partir do levantamento das informações, estas podem ser sistematizadas em forma de um texto, que, para um melhor entendimento, deve ser produzido seguindo a ordem cronológica das criações e acontecimentos relacionados ao tema.

Finalizado a produção desse recorte, o professor precisa avaliar como ele deve ser levado para sala de aula, pois se entende que:

\begin{abstract}
As potencialidades didáticas que emergem da história (...) têm em vista uma organização de ensino que procura articular o conhecimento matemático, historicamente contextualizado, juntamente com o currículo e o públicoalvo no ambiente escolar, tendo em consideração a intencionalidade do educador na elaboração de atividades para o ensino (SAITO, 2016, p. 8).
\end{abstract}

Nesse sentido, não se defende que o texto em si seja levado para sala de aula, ele pode ser a base para o desenvolvimento e a organização de situações de aprendizagem, pois diversas são as potencialidades didáticas da HM que poderão nortear caminhos para que haja essa inserção. Ou seja, não se propõe que o episódio seja apenas uma curiosidade para os alunos; antes, porém, deve ser parte integrante da aula a partir de atividades investigativas, situações-problema, produção de vídeos didáticos, atividades experienciais, dramatização por meio de teatros, entre outras possibilidades ${ }^{4}$. Indo ao encontro do que propõem Mendes e Chaquiam (2016), Miguel e Miorim (2008), Saito (2016), entre tantos outros pesquisadores da área.

Página Al| 288 mas delas estão descritas nos textos do Quadro 1 deste trabalho. 
Além disso, entende-se que intervenções como essas podem corroborar para a aprendizagem da Matemática, à medida que a $\mathrm{HM}$, quando inserida nas aulas, pode auxiliar na compreensão dos conceitos matemáticos, ademais de levar ao aluno compreender que a Matemática é uma construção humana, cheia de progressos, processos e está em constante evolução (GROENWALD, 2004). A exemplo, ambos os recortes foram explorados em dois momentos: em uma turma de terceira série do Ensino Médio, a partir de atividades investigativas; em um curso de formação continuada de professores de Matemática ${ }^{5}$, a partir de vídeos didáticos e atividades investigativas. Em ambas intervenções os resultados obtidos apontam que a HM auxiliou na compreensão dos conceitos matemáticos abordados, bem como auxiliou num posicionamento positivo frente ao que estava sendo proposto, evidenciando, assim, as potencialidades da HM enquanto recurso didático.

\section{ALGUMAS CONSIDERAÇÕES}

Diversas são as pesquisas que estão sendo desenvolvidas no campo da Educação Matemática que afirmam que a HM é um recurso didático valioso para a formação do aluno e, também, para a formação docente, pois a partir dela é possível compreender que a Matemática não é estática, mas se trata de uma ciência em constante evolução (DEIXA; SALVI, 2014). Além disso, essas pesquisas afirmam que a HM pode auxiliar na compreensão dos conceitos matemáticos, permitir a compreensão da evolução desses conceitos, possibilitar o entendimento de que a Matemática é uma construção humana, entre outras expectativas (GROENWALD, 2004).

Todavia, mesmo com tais potencialidades, as tentativas de lavá-la para a sala de aula, muitas vezes, esbarram em algumas dificuldades, dentre elas: a formação do professor, falta de material, falta de orientações didáticas para a sua inserção em sala de aula, e outras dificuldades que poderiam ser uma vez mais pontuadas. Reconhecendo tais impasses é que se propôs a presente pesquisa, cujo objetivo se voltou a indicar um caminho para se realizar recortes de episódios históricos, levando em consideração uma reflexão a respeito dos saberes docentes, que, a posteriori, podem ser utilizados em sala de aula.

Neste sentido, a presente proposta foi desenvolvida no intuito de possibilitar aos professores um olhar para os textos históricos (historiográficos ou originais) e fazer o recorte de episódios que possam ser inseridos nas aulas de Matemática, isto é, que sirvam de base para a elaboração de atividades que possam ser integradas as aulas, de modo que a HM possa exercer suas contribuições para o ensino dessa ciência.

Assim, a partir das exemplificações apresentadas, verifica-se que realizar esses recortes por meio dos saberes docentes é algo viável, mesmo que, evidentemente, não seja o único caminho; porém, tal estratégia mostrou-se de grande valia para a finalidade proposta. Ademais, os textos indicados no Quadro

${ }^{5}$ Uma reflexão mais abrangente dessa intervenção, bem como as atividades abordadas está disponível em: GOMES, L. F. Vídeos didáticos e atividades baseadas na história da matemática: uma proposta para explorar as geometrias não euclidianas na formação docente. 2017. 164 f. Dissertação (Mestrado em Ensino de Matemática), Universidade Tecnológica Federal do Paraná, Londrina, 2017. Disponível em: http://repositorio.utfpr.edu.br/jspui/bitstream/1/2404/1/LD PPGMAT M Gomes\%2C\%20Lucas\%20Ferreira 2017.pdf. Acesso em: Página $14 / 289 / 2018$. 
1 deste trabalho podem orientar o professor sobre a forma como estes recortes podem ser explorados, bem como a forma com a HM possa ser integrada às aulas de Matemática.

Acredita-se, desta maneira, ter alcançado o objetivo, sendo esta proposta mais uma alternativa para que esse recurso didático seja incorporado à formação de aluno e, também, à formação de professores. 


\title{
Clipping of historical episodes for math classes: a possible path
}

\begin{abstract}
Several researches argue that the History of Mathematics is a didactic resource that can contribute both to teacher training and to student training, in terms of understanding the content and Mathematics itself, among other aspects. However, even with such evidence, as a didactic resource, it is little explored in teacher training, with more emphasis on reflection on historical aspects. Moreover, even if such subjects have an interest in exploring it in their classes, they are faced with a lack of historical material, didactic orientations, suggestions of classes, among many elements that contribute to this resource not being explored. In this way, the present article aims to indicate a way to make cuts of historical episodes, taking into consideration a reflection on the teaching knowledge, which, a posteriori, can be used in the classroom. For this, this proposal is presented, through an exemplification: a cut of historical episodes about non-Euclidean geometries; making it possible to systematize the proposal.
\end{abstract}

KEYWORDS: History of Mathematics. You know teachers. Clipping of episodes. Mathematics education. 


\section{REFERÊNCIAS}

BARBOSA, L. N. S. C. de. Uma reconstrução histórico-filosófica do surgimento das geometrias não euclidianas. 2011. 58 p. Dissertação (Mestrado em Ensino de Ciências e Educação Matemática) - Universidade Estadual de Londrina, Londrina, 2011.

BLANCO, M. M. G. A formação inicial de professores de matemática: fundamentos para a definição de um curriculum. In: FIORENTINI, D. (Org.). Formação de professores de matemática: explorando novos caminhos com outros olhares. Campinas: Mercado de Letras, 2003. p. 51-86.

BOGDAN, R. C.; BIKLEN, S. Investigação qualitativa em educação. Porto: Porto Editora, p. 134-301, 1994.

BONOLA, R. Scientific Books: Non-Euclidean Geometry. Science, v. 36, p. 595-597, 1912.

BRASIL. Ministério da Educação. Secretaria de Educação Fundamental. Parâmetros Curriculares Nacionais: Matemática. Brasília: MEC/SEF, 1997.

BRITO, A. J. Geometrias não euclidianas: um estudo histórico pedagógico. 1995. 187 p. Dissertação (Mestrado em Educação) - Faculdade de Educação, Universidade Estadual de Campinas, Campinas, 1995.

BRITO, A. J.; CARVALHO, D. L. Utilizando a história no ensino de geometria. In: MIGUEL, A.; BRITO, A. de J.; CARVALHO, D. L.; MENDES, I. A. (Orgs.). História da matemática em atividades didáticas. São Paulo: Livraria da Física, 2009.

BURSAL, M. Turkish preservice elementary teacher's self-efficacy beliefs regarding mathematics and science teaching. International Journal of Science and Mathematics Education, Penang, v. 8, n. 4, 2010, p. 649-666.

CAMPELO, M. E. C. H. Alfabetizar crianças: um ofício, múltiplos saberes. 2001. 257 f. Tese (Doutorado em Educação) Natal, Centro de Ciências Sociais Aplicadas, Universidade Federal do Rio Grande do Norte, 2001.

COUTINHO, L. Convite às geometrias não euclidianas. 2. ed. Rio de Janeiro: Interciência, 2001.

DEIXA, G. V.; SALVI, R. F. Dificuldade dos professores em exercício no uso da história da matemática como alternativa didática para o ensino da matemática. 
Revista Científica da UEM: Série Ciências da Educação, v. 1, n. 1, p. 63-76, 2014.

D’AMBROSIO, U. A história da matemática: questões historiográficas e políticas e reflexos na Educação Matemática. In: BICUDO, M. A. V. (Org.). Pesquisa em Educação Matemática: concepções e perspectivas. São Paulo: UNESP, 1999. p. 97-115.

EUCLIDES. Os elementos. Tradução de Irineu Bicudo. São Paulo: Editora UNESP, 2009.

FELICIANO, L. F. O uso da História da matemática em sala de aula: o que pensam alguns professores do Ensino Básico. 2006. 171f. Dissertação (mestrado em ensino de Matemática), Universidade Estadual Paulista, Rio Claro, 2006.

FURINGUETTI, F. Teacher education through the history of mathematics. Educational Studies in Mathematics, Dordrecht, n. 66, p. 131-143, 2007.

GARBI, G. G. A rainha das ciências: um passeio histórico pelo maravilhoso mundo da matemática. 5. ed. São Paulo: Livraria da Física, 2010.

GARNICA, A. V. M. História oral e educação matemática. In: ARAÚJO, J. L.; BORBA, M. C. (Org.). Pesquisa qualitativa em educação matemática. Belo Horizonte: Autêntica, p. 77-98, 2004.

GAUTHIER, C. Por uma teoria da Pedagogia, pesquisas contemporâneas sobre o saber docente. 2. ed. Rio Grande do Sul: Unijui, 2006.

GROENWALD, C. L.S. Perspectivas em Educação Matemática. Canoas: Ulbra, 2004.

HANSEN, V. L. Everlatig Geometry. In: MAMMANA, Carmelo; VILLANI, Vinicio (Ed.). Perspectives on the teaching of geometry for the 21st century: an ICMI study. Dordrecht, Boston, London: Kluwer Academic Publishers, 1998.

KATZ, V. J. A História da Matemática: uma introdução. Lisboa: Fundação Calouste Gulbenkian, 2011.

MAN-KEUNG, S. Official curriculum in mathematics in Ancient China: How did candidates study for the examination? Ed: Fan Lianghuo, Wong Ngai-Ying, Cai Jinfa, and Li How Chinese learn mathematics. Perspective from insiders, Shiqi, 
MENDES, I. A. A investigação histórica como agente de cognição matemática na sala de aula. In: MENDES, I. A.; FOSSA, J. A.; VALDÉS, J. E. Nápoles. A História como um agente de cognição na Educação Matemática. Porto Alegre: Sulina, 2006.

MENDES, I. A.; CHAQUIAM, M. História nas aulas de matemática: fundamentos e sugestões didáticas para professores. Belém: SNHMat, 2016.

MIGUEL, A.; MIORIM, M. A. História na educação matemática: propostas e desafios. Belo Horizonte: Autêntica, 2008.

NOBRE, S. R. Leitura crítica da história: reflexões sobre a história da matemática. Ciência \& Educação, Bauru, v. 10, n. 3, p. 531-543, 2004.

Introdução histórica às geometrias não euclidianas: uma proposta pedagógica. Belém: SBHMT, 2009.

PARANÁ. Secretaria de Estado da Educação. Diretrizes Curriculares de Matemática para a Educação Básica. Curitiba: SEED, 2008.

RIBEIRO, R. D. G. L. O ensino das geometrias não-euclidianas: um olhar sob a perspectiva da divulgação científica. 2012. 102f. Dissertação (Mestrado em Ensino de Ciências e Matemática) - Faculdade de Educação, Universidade São Paulo, São Paulo, 2012.

SAITO, F. História e ensino de matemática: construindo interfaces. In: J. Flores Salazar \& F. Ugarte Guerra (eds.). Investigaciones en Educación Matemática. Lima: Fundo Editorial PUCP, 2016, pp. 237- 291.

STAMATO, J. M. A. A disciplina História da Matemática e a Formação do Professor de Matemática: dados e circunstâncias de sua implantação na Universidade Estadual Paulista, campi de Rio Claro, São José do Rio Preto e Presidente Prudente. 2003. 197f. Dissertação (mestrado em Educação Matemática) - Instituto de Geociências e Ciências Exatas, Universidade Estadual Paulista, Rio Claro, 2003.

TARDIF, M. Saberes docentes e formação profissional. 15. ed. Rio de Janeiro: Vozes, 2013. 
epistemologia. In: SEMINÁRIO DE PESQUISA SOBRE O SABER DOCENTE, Fortaleza, 1996. Anais... Fortaleza: UFCE, 1996.

Recebido: 2017-06-19

Aprovado: 2018-04-15

DOI: $10.3895 /$ rbect.v11n3.6032

Como citar: ARAMAN, E. M. O.; GOMES, L. F. Recorte de episódios históricos para as aulas de matemática: um caminho possível. Revista Brasileira de Ensino de Ciência e Tecnologia, v. 11, n. 3, 2018. Disponível em:

<https://periodicos.utfpr.edu.br/rbect/article/view/6032>. Acesso em: xxx.

Correspondência: Eliane Maria de Oliveira Araman - elianearaman@utfpr.edu.br

Direito autoral: Este artigo está licenciado sob os termos da Licença Creative Commons-Atribuição 4.0 Internacional.

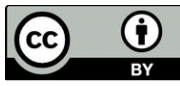

